\title{
Expansão das escolas e colégios militares retoma a lógica da exclusão
}

\section{Expansion of military schools resumes the logic of exclusion Expansión de las escuelas y colegios militares retoma la lógica de la exclusión}

MARIA DO HORTO SALLES TIELLET

Resumo: $\mathrm{O}$ artigo analisa o processo de expansão das escolas militares, através dos argumentos dos agentes públicos, na perspectiva da pesquisa exploratória de cunho descritivo. Foram realizadas buscas sobre o assunto entre o ano de 2015 e 2018, em jornais de circulação estadual, notícias postadas em sites oficiais. Para a análise do material aplicou-se a Análise de Conteúdo de Laurence Bardin, que possibilitou a constatação de que a justificativa para a expansão das escolas militares está a qualidade do ensino, que nunca foi prioridade das políticas educacionais do Estado de Mato Grosso.

Palavras-chave: escola militar; Escola militar Tiradentes; Escola militar Dom Pedro II; Polícia Militar do Mato Grosso.

Abstract: The article analyzes the expansion process of military schools through public agents arguments from the exploratory perspective of descriptive nature. A survey on the subject was carried out between the years 2015 and 2018 in newspapers with circulation in the state, news posted in official web pages. The analysis of the material was made through the Content Analysis by Laurence Bardin that led to finding out that, in the core of the justification for the expansion of military schools, lies the quality of education which never was a priority of educational policies of the state of Mato Grosso.

Keywords: military school; Tiradentes Military School; Dom Pedro II Military School; Military Police of Mato Grosso.

Resumen: El artículo analiza el proceso de expansión de las escuelas militares, a través de los argumentos de los agentes públicos, desde la perspectiva de la investigación exploratoria de carácter descriptivo. Se realizaron búsquedas acerca del tema entre los años 2015 y 2018, en periódicos de difusión estadual, noticias publicadas en sitios electrónicos oficiales. Para el análisis del material, se aplicó el Análisis de Contenido de Laurence Bardin, que permitió constatar que la justificativa para la expansión de las escuelas militares está la calidad de la enseñanza que nunca fue prioridad en las políticas educativas del Estado de Mato Grosso.

Palabras-clave: escuela militar. Escuela Militar Tiradentes. Escuela Militar Dom Pedro II. Policía Militar de Mato Grosso. 


\section{INTRODUÇÃO}

Neste artigo, trata-se da expansão das escolas militares defendida por agentes públicos, na perspectiva de uma pesquisa exploratória de cunho descritivo, com o objetivo de conhecer a justificativa e os critérios do processo de expansão de tais escolas no Estado de Mato Grosso. Para tanto, fez-se o levantamento de material sobre o assunto, realizando buscas, entre o período de 2015 e 2018, em jornais de circulação estadual, notícias postadas em sites oficiais da Educação, da Segurança, da PMMT, do Corpo de Bombeiros Militar e da Assembleia Legislativa do Estado de Mato Grosso, sendo que a escolha do corpus da pesquisa ocorreu pela aplicação das regras de Representatividade e Pertinência da Análise de Conteúdo de Bardin (2010).

Para a busca de material documental, nos sites mato-grossenses, utilizouse o descritor "escolas militares", obtendo-se número maior de documentos com esse descritor do que o descritor "militarização das escolas".

Inicialmente, apresenta-se a caracterização do modelo já consolidado no país de escolas e colégios militares, exemplificando-se com as escolas militares de Mato Grosso; em sequência, discorre-se sobre a expansão dessas escolas e colégios militares no Mato Grosso e, por fim, explora-se o resultado da análise do corpus selecionado.

\section{O MODELO CONSOLIDADO DE ESCOLA E DE COLÉGIO MILITAR}

As escolas e colégios militares são instituições que se reportam às Forças Armadas ou se subordinam, administrativamente, à Polícia Militar. Esse modelo de ensino militar já está consolidado no país e é de conhecimento da população.

Em termos gerais, sabe-se que a proposta pedagógica desse modelo tem o objetivo de orientar os alunos para os valores e tradições da educação militar, visando à carreira militar. E seu quadro docente é composto, preferencialmente, por militares do exército ou da polícia militar.

O modelo iniciou sua atividade atendendo os dependentes de militares do Exército, da Polícia Militar e, posteriormente ampliou a oferta de vagas para a população em geral, adotando edital público para a seleção dos estudantes. Assim, a família que concorre a tais editais de seleção opta por uma formação para a carreira militar de seu filho. E este, por sua vez, sabe que para permanecer nessa escola precisa cumprir com o estabelecido no Código de Conduta existente nesse tipo de estabelecimento de ensino. 
Para abrigar o conjunto de ações e atividades desenvolvidas próprias desse modelo educacional, constroem-se prédios visando a uma estrutura física específica. Por isso, os estudantes de Colégios ou Escolas Militares custam mais caro para o País (CAFARDO; JANSEN, 2018). A peculiaridade desse modelo de escola/colégio não se limita a essa estrutura física, tampouco ao pedagógico, mas, principalmente ao financeiro. Esse modelo de instituição de ensino é diferenciado e tem objetivos claros - a formação militar, com base na disciplina, ordem e hierarquia.

É preciso destacar que há cobranças de mensalidade em Colégios Militares, pois neles não incide o artigo da Constituição que prevê gratuidade do ensino público. Nesse sentido, esses Colégios têm uma natureza própria e, por isso, não podem ser considerados escolas públicas. A lei prevê que os recursos para manutenção dos Colégios Militares do Exército são do Ministério da Defesa e com verbas extraorçamentárias, ou seja, com a cobrança mensal dos alunos. A Advocacia-Geral da União (AGU), mencionando dados de 2018, declarou que "a arrecadação da cota mensal representa $47 \%$ da verba total dos 13 colégios militares [da competência do Exército] que há no país. A cobrança é de R $\$ 226$ no Ensino Fundamental e R\$251 no Ensino Médio" (TEIXEIRA; CARNEIRO, 2018, p.1).

No caso das escolas e dos colégios militares da Polícia Militar, os recursos para manutenção são definidos em legislação específica de cada Estado da Federação.

No modelo apresentado, o Estado de Mato Grosso não tem qualquer escola de abrangência do Exército, somente da Polícia Militar: Escola Estadual da Polícia Militar “Tiradentes” e a Escola Estadual Dom Pedro II.

\section{ESCOLA ESTADUAL DA POLÍCIA MILITAR “TIRADENTES”}

No ano de 1986, foi criada, em Cuiabá a Escola Estadual de $1^{\circ}$ Grau da Polícia Militar "Tiradentes", dirigida por civis, sem qualquer ligação com a Polícia Militar. Em 1990, a escola foi nomeada Escola Preparatória de I e II Graus da Polícia Militar "Tiradentes", subordinada, administrativamente, à PMMT. No ano 2000, através do Decreto $n^{\circ} 1.826$ de 11 de outubro, passou a denominarse Escola Estadual da Polícia Militar "Tiradentes” (POLICIA MILITAR,2019) embora documentos recentes da PMMT usem a denominação 'colégio'.

A partir da administração do governador Sinval Barbosa (2010-2014), diferentes disposições legais da PMMT foram reformuladas, consolidando a Escola Estadual da Polícia Militar "Tiradentes" (EEPM Tiradentes), ao se incorporá-la à Estrutura Organizacional Básica da PMMT, no Nível de Apoio, 
constituído por órgãos que atendem as necessidades de formação, capacitação, pesquisa, saúde, assistência social, cultura e projetos, atuando em cumprimento das diretrizes e ordens dos órgãos de direção, de acordo com o art. 4 da Lei Complementar n. 386, de 5 de março de 2010 (MATO GROSSO, 2010a, p.2).

Ao ser incluída na estrutura organizacional da PMMT, a EEPM "Tiradentes" assumiu papel importante na Corporação, sendo uma das instâncias de formação a integrar o Sistema de Ensino da Polícia e do Corpo de Bombeiros Militares do Estado de Mato Grosso, através da Lei Complementar n. 408 de $1^{\circ}$ de julho de 2010, no que trata o art. 63. (MATO GROSSO, 2010b, p. 23).

Assim, as escolas militares de Mato Grosso se subordinam à Polícia Militar do Estado de Mato Grosso (PMMT) e ao Corpo de Bombeiros Militares do Estado de Mato Grosso (CBMMT), através da Diretoria de Ensino, Instrução e Pesquisa (DEIP), tendo como mantenedora a Secretaria de Estado de Educação de Mato Grosso (SEDUC), em parceria com a Secretaria de Estado e Segurança Pública de Mato Grosso (SESP).

A finalidade dessas escolas consta na Lei Complementar 408 de julho de 2010 que institui um sistema de ensino próprio da Polícia Militar e do Corpo de Bombeiro do Estado de Mato Grosso. A finalidade é (art.1 ${ }^{\circ}$ ) "qualificar recursos humanos necessários a ocupação de cargos e para desempenho de funções previstas na Lei de Organização Básica (LOB) da Polícia e do Corpo de Bombeiro Militar do Estado de Mato Grosso" (MATO GROSSO, 2010b). Tal finalidade se expressa na filosofia e nos objetivos dessas escolas destacando o aprimoramento da carreira militar a partir do ingresso na Educação Básica, descrito nos seguintes termos:

[...] dar ao educando uma cultura solidificada na disciplina e na hierarquia militar, [...] proporcionando uma visão consciente da democracia formando o futuro cidadão para o exercício prévio da cidadania. (POLÍCIA MILITAR, 2000, p.1, grifo nosso).

No ano de 2014, o Estatuto dos Militares do Estado de Mato Grosso, reformulado pela Lei Complementar no 555 de 29 de dezembro 2014 (MATO GROSSO,2014) - reafirma a existência de um sistema de ensino próprio da polícia militar nos termos da legislação específica e/ou peculiar, mantendo no parágrafo $1^{\circ}$ do art. 195, o Colégio Tiradentes no âmbito da Polícia Militar. A Escola 'Tiradentes' tem seu funcionamento gerido pelo regime militar, o que a diferencia das demais escolas da rede pública de ensino. A escola é destinada a filhos e dependentes legais de militares, sendo-lhes reservadas $50 \%$ das vagas, e o restante é oferecido a civis. (MATO GROSSO, 2015). Esse é o modelo consolidado no Estado de Mato Grosso. 


\section{O MODELO NOVO DE ESCOLAS E COLÉGIOS MILITARES}

No país, está em expansão outro modelo, uma variante, um híbrido, que não tem nem definição nem objetivos claros e tem sido denominado de diferentes maneiras: Colégio Militar (confundindo-se, assim, com o modelo já consolidado); Escola de 'gestão militar' e Escola 'cívico-militar'.

Durante a campanha eleitoral de 2018, o então, Deputado Federal, candidato à Presidência da República, Jair Bolsonaro, prometeu expandir o modelo, afirmando que "há um preconceito quando se fala sobre as escolas coordenadas por militares [...] Já foi mais do que provado o sucesso deste modelo". (PACHECO, 2019, p.1). Quando Jair Bolsonaro assumiu a presidência do País criou, no Ministério da Educação a subsecretaria de Fomento às Escolas CívicoMilitares, sob a direção de uma militar ${ }^{1}$, com o objetivo de: Promover a adesão do modelo de escola nos padrões de ensino e modelos pedagógicos empregados nos colégios militares do exército, polícias militares e corpo de bombeiros". (BRANDÃO, 2019, p.1).

A criação de uma Secretaria no MEC para fomentar as Escolas CívicoMilitares nos coloca frente aos seguintes questionamentos: a Escola CívicoMilitar é uma nova denominação do modelo consolidado de Escolas Militares gerenciadas pelo Exército, e as denominadas Escolas de Gestão-militar ou Gestão-compartilhada são dirigidas por policiais militares? Ou a denominação é para um novo modelo de gestão, com a participação de militares do exército ou da polícia militar, a ser executado por adesão das escolas da rede pública? $\mathrm{O}$ que nos parece é que o sentido dado pela subsecretaria de Fomento às Escolas Cívico-Militares à adesão voluntária está se referindo a escolas públicas, expresso na afirmação da Secretária de que o modelo atenderá "preferencialmente, escolas em situação de vulnerabilidade social” (BRANDÃO, 2019, p.1), significando isso que o foco dessa política será a escola da rede pública.

A Confederação Nacional dos Trabalhadores em Educação (CNTE) destacou que as escolas públicas civis transformadas em escolas militares pelos governos estaduais são diferentes dos colégios militares tradicionais, que fazem parte da rede de ensino das Forças Armadas ou das PMs estaduais. A CNTE vê a apropriação das escolas pela gestão militar como um sério risco para a consolidação de uma educação pública, laica e de valores republicanos. 
Implanta-se nessas escolas uma nova pedagogia: o militarismo. [...] a substituição de professores e diretores de carreira por gestores e professores militares é promovida por forças políticas conservadoras e antidemocráticas que têm ferido a Constituição. (CAMPOREZ, 2018, p.15).

Em quatorze unidades da federação, no período de 2013 a 2018, o número de escolas públicas militares, saltou de trinta e nove (39) para cento e vinte e duas (122), de acordo com Camporez (2018). Ainda, segundo o autor, "O fenômeno se reproduz por todo o país, mas com mais intensidade nos Estados do Norte e do Centro-Oeste", sendo que o total de escolas geridas pela Polícia Militar (PM) cresceu 212\% em cinco anos" (CAMPOREZ, 2018, p. 1). Segundo diagnóstico da Subsecretaria de Fomento às Escolas Cívico-Militares, atualmente, no país, há 234 escolas militares.

A expansão das escolas militares no Estado de Goiás e de Minas Gerais é a mais emblemática. Serve de referência para o estudo do delineamento do novo modelo de escolas que tem apoio do Governo Bolsonaro.

No caso do Estado de Goiás, segundo Alves, Toschi e Ferreira, foi "uma política exclusiva do governador Marconi Perillo, que implantou 46 unidades de colégios militares, criando, até abril de 2018, [...] mais 32 unidades. A expansão é vertiginosa." (ALVES; TOSCHI; FERREIRA,2018, p. 277).

A expansão de escolas militarizadas, na perspectiva do Exército ou da Polícia Militar, com a aquiescência de agentes públicos, não apresenta critérios, justificativas e objetivos claros, pois, esses se alteram ao longo dos anos, afirmam Alves; Toschi; Ferreira (2018), de maneira a atender as demandas políticas, sejam elas advindas da elite ou das inquietações populares, fruto da insegurança, do medo e da violência.

Nessa nova configuração, ao se transferirem escolas públicas da rede municipal ou estadual para o gerenciamento militar, ocorrem relações oriundas da presença militar (Exército ou Polícia Militar), as quais alteram a estrutura de gestão das escolas. Isto é, os militares assumem a tarefa de disciplinar e as atividades administrativas, sendo o diretor indicado pela Instituição Militar de Ensino, enquanto os professores (civis) respondem pela parte didático-pedagógica, o que desfaz uma das grandes conquistas dos professores: a gestão democrática.

O segundo problema é que o novo modelo vai estabelecer, no interior da rede pública de ensino, escolas diferenciadas ou subsistemas. Escola pública para uma elite e escolas públicas para filhos de famílias de baixa renda. As escolas para a elite são as escolas militares, bem equipadas, seguras, e apresentando uma educação de qualidade que se contrapõe a outras escolas públicas reservadas, possivelmente, para os mais pobres, nas mesmas ou em piores condições em que se encontram. 
Às famílias que não têm recursos para custear a escola militar ou que tiverem seus filhos excluídos por não se ajustarem ao código de conduta das mesmas, restará o modelo de escola pública que temos: sucateada, abandonada pelo poder público, desvalorizada, com um quadro docente desmotivado.

Para muitas dessas crianças que serão excluídas, a escola seria o único lugar que as protegeria do convívio com a criminalidade. Expulsas dela, não terão saída. Mesmo que se dirijam a outra escola, chegarão lá já estigmatizadas e continuarão seu processo de exclusão. (FREITAS, 2019, p.1).

Ocorre que os filhos de um largo conjunto da população, que poderão ser excluídos das escolas militares, têm a escola como o único lugar que os protegeria do convívio com a criminalidade. Assim, a militarização das escolas e seu código de conduta criam uma linha direta para a prisão de estudantes pobres e negros, de acordo com Freitas (2019).

\section{EXPANSÃO DAS ESCOLAS MILITARES NO ESTADO DE MATO GROSSO}

A aproximação do governo do Estado com a Corporação Militar - Polícia e Bombeiros - atendendo suas demandas, marcou o início na gestão de Blairo Maggi. No primeiro mandato do seu governo, foi criada a Escola Estadual Dom Pedro II, integrando a estrutura organizacional do Corpo de Bombeiro Militar do Estado de Mato Grosso - Lei n. 8.171, de 22 de julho de 2004 (MATO GROSSO, 2004).

A competência pela manutenção da Escola Estadual Dom Pedro II foi dividida entre três Secretarias de Estado: de Justiça e Segurança Pública (SEJUSP); de Educação (SEDUC) e de Trabalho, Emprego e Cidadania (SETEC), sendo que os recursos financeiros, sob a gestão do Fundo de Reequipamento do Corpo de Bombeiros Militar (FREBOM), provém do Fundo Estadual de Educação (FEE), do Ministério de Educação e do próprio FREBOM.

\footnotetext{
Art. $4^{\text {o }}$ Compete à Secretaria de Estado de Justiça e Segurança Pública, através do Corpo de Bombeiros Militar, manter a direção, a coordenação, o corpo administrativo e a manutenção das instalações físicas da escola. [...]

Art. $5^{\circ}$ Compete à Secretaria de Estado de Educação - SEDUC, oferecer recursos humanos necessários ao funcionamento da referida escola, bem como promover a eleição do Conselho Deliberativo da comunidade escolar. [...] Art. $6^{\circ}$ Compete à Secretaria de Trabalho, Emprego e Cidadania, a disponibilização de instalação física adequada para a implantação da unidade escolar, bem como o planejamento e a execução de projetos de qualificação profissional e de cidadania. (Idem, p.1).
} 
Repasses de recursos da Secretaria de Estado de Educação para a Secretaria de Estado de Justiça e Segurança Pública têm sido uma prática sem questionamentos por parte da sociedade, de seus representantes e mesmo do Ministério Público. Em 2009, o Secretário de Educação fez um repasse de recursos da Secretaria de Estado da Educação (SEDUC) para a Secretaria de Estado de Justiça e Segurança Pública (SEJUSP) / PMMT $^{2}$, em apoio às ações, aos programas e aos projetos desenvolvidos nas escolas públicas pelas polícias Militar e Judiciária Civil, que objetivavam a prevenção dos conflitos e da violência no interior das escolas. Também manifestou apoio à criação, em Cuiabá, de mais uma escola do PMMT. A escola militar proposta, em 2009, não foi criada.

O Governo de Mato Grosso vai construir mais um colégio militar em Cuiabá, a sede da escola Tiradentes 2 será no bairro Pedra 90. O anúncio foi oficializado [...] pelos secretários de Estado Eumar Novacki (Casa Civil e Comunicação Social), Ságuas Moraes (Educação) e Diógenes Curado Filho (SEJUSP), durante audiência no gabinete da Casa Civil. O secretário Ságuas Moraes revelou que já foi escolhido o terreno para a construção do prédio, nos moldes da escola atrativa com piscina, quadra coberta, 12 salas de aula e praça de alimentação. A intenção do Governo do Estado, adiantou Ságuas Moraes, é licitar a obra até o segundo semestre deste ano para começar a construí-la até o fim do ano (MATO GROSSO, 2009, p,1).

Durante o governo de Pedro Taques (2015-2018), o número de escolas do modelo militar cresceu no país e no Estado de Mato Grosso, sendo que a expansão ocorreu no âmbito administrativo da Polícia Militar.

No ano de 2015, o Conselho Estadual de Educação (CEE/MT) fixou normas de estrutura, organização e funcionamento dos Colégios Militares para oferta de Educação Básica do Sistema Estadual de Ensino de Mato Grosso Resolução Normativa no 005/2015- CEE/MT (MATO GROSSO, 2015), que anunciou ser competência também dos Colégios Militares ministrar o Ensino Fundamental e Médio a alunos de ambos os sexos, filhos ou dependentes legais de militares da Polícia Militar e do Corpo de Bombeiros Militar do Estado de Mato Grosso, e para a população civil através de edital de seleção (art. $2^{\circ}$, Inciso I).

Os colégios militares deveriam estabelecer regime de colaboração mútua, visando à gestão compartilhada entre a SEDUC e a Secretaria de Estado da Segurança Pública (SESP), sendo que as atribuições da Secretaria de Estado de Educação deveriam ser, entre outras, disponibilizar profissionais da Educação 
Básica para compor o quadro de pessoal dos colégios militares; assegurar os repasses de recursos públicos destinados à educação e disponibilizar espaço físico e manutenção das unidades de ensino dos Colégios Militares. Enquanto que a atribuição da Secretaria de Estado de Segurança Pública seria ceder espaço físico, quando houvesse disponibilidade, além de disponibilizar recursos humanos para atuar na direção, na coordenação pedagógica e demais funções, sendo essas funções indicadas pela corporação.

As despesas para a manutenção e funcionamento regular dos Colégios deverão ser feitas em dotações orçamentárias previstas na Secretaria de Estado de Educação e na Secretaria de Estado de Segurança Pública, (art. $4^{\circ}$ ). O que se apreende do art. $4^{\circ}$ e do art. $3^{\circ}$ e seus incisos é que os recursos da educação, já reduzidos, serão alocados e divididos com uma escola que atende uma elite.

\begin{abstract}
As efetivas condições de funcionamento dos colégios militares são muito distintas das escolas estaduais: possuem excelente infraestrutura física [...]. Enquanto isso, as escolas estaduais convivem com a precariedade da infraestrutura, a falta de pessoal. Assim, a um pequeno grupo, o dos colégios militares, é garantida uma educação pública diferenciada, enquanto a maioria da população convive com a precariedade da escola e o abandono do poder público. Nesse processo, a desvalorização da escola pública vai acontecendo paulatinamente e a ela vai sendo atribuído um lugar social marginalizado na sociedade. (ALVES; TOSCHI; FERREIRA, 2018, p.284).
\end{abstract}

Não há recursos para a instalação de novas escolas públicas e, para resolver o problema da expansão das escolas militares, utilizam-se as instalações das escolas públicas existentes, direcionando-as para um grupo, para uma elite.

Nesses Colégios, serão destinadas 50\% das vagas para filhos e dependentes de militares da Polícia Militar e do Corpo de Bombeiros aprovados no processo seletivo, enquanto as demais vagas serão ocupadas pelos demais candidatos aprovados ( $\$ 2^{\circ}$, art.6).

A Resolução Normativa n ${ }^{\circ}$ 005/2015, de 29 de setembro de 2015, do Conselho Estadual de Educação (CEE/MT), incentivou a criação de novas escolas militares no Estado. No ano de 2016 iniciaram-se audiências públicas para a criação de escolas militares no interior (ANDRADE, 2016, p.1), sendo programadas audiências para 2017.

Pedro Taques, em março de 2017, assinou o decreto que criou três unidades da Escola Estadual "Tiradentes" da Polícia Militar nos municípios de Sorriso, Confresa e Juara, no mesmo ano incluiu a unidade de Nova Mutum no Decreto (SANTANA, 2017). 
No ano de 2017 e de 2018 passaram a tramitar, na Assembleia Legislativa do Mato Grosso, nove projetos para a implantação de Unidades da Escola Estadual da Polícia Militar “Tiradentes” (Quadro 1).

\section{Quadro 1 - Relação de projetos para implantação de Unidades da Escola Estadual da Polícia Militar "Tiradentes”, em tramitação, na Assembleia Legislativa de Mato Grosso (ALMT), no período de 2015 - 2018}

\begin{tabular}{|c|c|c|c|c|}
\hline PROPOSIÇÃO & ANO & $\begin{array}{c}\text { NOME DO } \\
\text { DEPUTADO }\end{array}$ & $\begin{array}{c}\text { N. DO } \\
\text { PROTOCOLO }\end{array}$ & SITUAÇÃO \\
\hline $\begin{array}{l}\text { Nos termos do Artigo } 160 \text { e seguintes do Regimento Interno } \\
\text { desta Casa de Leis, requeiro a Mesa Diretora, após ouvido o } \\
\text { soberano plenário, que encaminhe expediente indicatório ao } \\
\text { Excelentíssimo Governador do Estado de Mato Grosso Senhor } \\
\text { Pedro Taques e ao Secretário de Estado de Educação, Esporte } \\
\text { e Lazer Marco Aurélio Marrafon, que viabilize estudos para a } \\
\text { construção de um Colégio Militar no Município de Pontes e } \\
\text { Lacerda. }\end{array}$ & 2017 & $\begin{array}{l}\text { Wancley } \\
\text { Carvalho }\end{array}$ & 3429 & $\begin{array}{c}\text { Em } \\
\text { tramitação }\end{array}$ \\
\hline $\begin{array}{l}\text { Indico ao Poder Executivo, mostrando a urgente e imprescindível } \\
\text { necessidade de se tomar providências que culminem com a } \\
\text { implantação de uma Unidade da Escola Estadual de Polícia } \\
\text { Militar "Tiradentes" no Município de Cáceres. }\end{array}$ & 2017 & $\begin{array}{l}\text { Sebastião } \\
\text { Rezende }\end{array}$ & 2522 & $\begin{array}{c}\text { Em } \\
\text { tramitação }\end{array}$ \\
\hline $\begin{array}{l}\text { Indico ao Poder Executivo, mostrando a urgente e imprescindível } \\
\text { necessidade de se tomar providências que culminem com a } \\
\text { implantação de uma Unidade da Escola Estadual da Polícia } \\
\text { Militar "Tiradentes" no Município de Rondonópolis. }\end{array}$ & 2017 & $\begin{array}{l}\text { Sebastião } \\
\text { Rezende }\end{array}$ & 53 & Criada \\
\hline $\begin{array}{l}\text { Indico ao Poder Executivo, mostrando a urgente e imprescindível } \\
\text { necessidade de se tomar providências que culminem com a } \\
\text { implantação de uma Unidade da Escola Estadual de Polícia } \\
\text { Militar "Tiradentes" no Município de Várzea Grande. }\end{array}$ & 2017 & $\begin{array}{l}\text { Sebastião } \\
\text { Rezende }\end{array}$ & 52 & $\begin{array}{c}\text { Em } \\
\text { tramitação }\end{array}$ \\
\hline $\begin{array}{l}\text { Indico ao Poder Executivo, mostrando a urgente e imprescindível } \\
\text { necessidade de se tomar providências que culminem com a } \\
\text { implantação de uma Unidade da Escola Estadual de Polícia } \\
\text { Militar "Tiradentes" no Município de Sinop. }\end{array}$ & 2017 & $\begin{array}{l}\text { Sebastião } \\
\text { Rezende }\end{array}$ & 51 & $\begin{array}{c}\text { Em } \\
\text { tramitação }\end{array}$ \\
\hline $\begin{array}{l}\text { Indico ao Poder Executivo, mostrando a urgente e imprescindível } \\
\text { necessidade de se tomar providências que culminem com a } \\
\text { implantação de uma Unidade da Escola Estadual de Polícia } \\
\text { Militar "Tiradentes" no Município de Barra do Garças. }\end{array}$ & 2017 & $\begin{array}{l}\text { Sebastião } \\
\text { Rezende }\end{array}$ & 59 & Criada \\
\hline $\begin{array}{l}\text { Indico ao Poder Executivo, mostrando a urgente e imprescindível } \\
\text { necessidade de se tomar providências que culminem com a } \\
\text { implantação de uma Unidade da Escola Estadual de Polícia } \\
\text { Militar "Tiradentes" no Município de Tangará da Serra. }\end{array}$ & 2017 & $\begin{array}{l}\text { Sebastião } \\
\text { Rezende }\end{array}$ & 49 & $\begin{array}{c}\text { Em } \\
\text { tramitação }\end{array}$ \\
\hline $\begin{array}{l}\text { Indico ao Poder Executivo, mostrando a urgente e imprescindível } \\
\text { necessidade de se tomar providências que culminem com a } \\
\text { implantação de uma Unidade da Escola Estadual de Polícia } \\
\text { Militar "Tiradentes" no Município de Água Boa. }\end{array}$ & 2018 & $\begin{array}{l}\text { Sebastião } \\
\text { Rezende }\end{array}$ & 5223 & $\frac{E m}{\text { tramitação }}$ \\
\hline $\begin{array}{l}\text { Indico ao Poder Executivo, mostrando a urgente e imprescindível } \\
\text { necessidade de se tomar providências que culminem com a } \\
\text { implantação de uma Unidade da Escola Estadual da Polícia } \\
\text { Militar "Tiradentes" no Município de Canarana - MT. }\end{array}$ & 2018 & $\begin{array}{l}\text { Sebastião } \\
\text { Rezende }\end{array}$ & 137 & $\underset{\text { tramitação }}{E m}$ \\
\hline
\end{tabular}

Fonte: Assembleia Legislativa. Elaborado pela Autora. 
Em 2018, houve a expansão das unidades da Escola Estadual "Tiradentes" da Polícia Militar para Lucas do Rio Verde, Barra do Garças e Rondonópolis. E a exemplo da Escola Estadual "Tiradentes" da Polícia Militar, em 5 de abril de 2018, pelo Decreto no 1.427 (MATO GROSSO, 2018), criou-se a Escola Estadual Dom Pedro II, primeira unidade de ensino do Corpo de Bombeiros Militar (CBMMT), no Estado de Mato Grosso. Essa escola foi inaugurada em agosto de 2018, como resultado de uma parceria entre Corpo de Bombeiros Militar e Governo Estadual, através da Secretaria de Estado de Educação e da Prefeitura Municipal de Alta Floresta.

A Escola Estadual Dom Pedro II compunha o organograma do CBMMT, e integrou o Sistema de Ensino da Polícia e do Corpo de Bombeiro Militar do Estado de Mato Grosso - Lei Complementar n. 408, de $1^{\circ}$ de julho de 2010 -, no que trata o art. 63 (MATO GROSSO, 2010b, p.23), cujo objetivo, entre outros, era o de despertar vocações para a carreira de bombeiro-militar (MATO GROSSO, 2004, p.1). Institucionalizada de acordo com o Estatuto dos Militares do Estado de Mato Grosso reformulado - Lei Complementar n.555, de 29 de dezembro de 2014 (MATO GROSSO, 2014) - documento que reafirma a existência de um sistema de ensino próprio, nos termos de legislação específica e/ou peculiar, mantendo, no parágrafo 1, do art. 195, que o Colégio Dom Pedro II constitui-se em modelo de ensino do CBMMT.

A criação da Escola Estadual Militar do Corpo de Bombeiros Dom Pedro II é decorrência da Resolução Normativa no 005/2015, de 29 de setembro de 2015, do Conselho Estadual de Educação (MATO GROSSO, 2015) que fixou as normas de estrutura, organização e funcionamento dos Colégios Militares para a oferta de Educação Básica do Sistema Estadual de Ensino de Mato Grosso.

Há diferentes denominações para as instituições de ensino do Corpo de Bombeiros e da Polícia Militar. No edital de seleção, a denominação Escola Estadual Militar do Corpo de Bombeiros Dom Pedro II, e em outros documentos da corporação, a denominação muda para Colégio Dom Pedro II do Corpo de Bombeiros Militar do Estado de Mato Grosso (CBMMT), e a instituição de ensino da PMMT é identificada como Colégio Militar Tiradentes.

Independente do nome com que são identificadas as escolas, as instituições de ensino militar seguem as regras definidas na Resolução Normativa n ${ }^{\circ}$ 005/2015, de 29 de setembro de 2015, do Conselho Estadual de Educação (CEE/MT), além de serem fiscalizadas e controladas pela PMMT através da Diretoria de Ensino, Instrução e Pesquisa (DEIP) e das suas Coordenadorias. 
As escolas militares reservam vagas para filhos e dependentes legais de militares, em até $50 \%$, e o restante é destinado ao público em geral. E o diretor das escolas militares deve ser um militar, indicado mediante processo de escolha e nomeado pela Corporação.

Ainda, tendo como referência a Resolução Normativa n. 005/2015CEE/MT, questiona-se:

Por que para as despesas de manutenção e funcionamento dos colégios somente a SEDUC tem o dever de assegurar os repasses de recursos públicos destinados à educação, quando a rede de ensino público reivindica mais recursos para a melhoria das condições de funcionamento, da infraestrutura precarizada e do déficit de pessoal das escolas da rede pública?

Qual o impacto para o Estado, do ponto de vista orçamentário, educacional e de segurança, com a expansão desse modelo de colégio criado em Nova Mutum, Sorriso, Confresa, Lucas do Rio Verde, Sinop, Cuiabá, Alta Floresta, Barra do Bugres e Rondonópolis, que privilegia uma parcela pequena da população que a elas pode ter acesso e nelas se manter?

Qual o custo social desse modelo excludente de escola, que nega o direito à educação pública e de qualidade para filhos de grande parcela da população?

Quais são as justificativas e os critérios adotados para a expansão das escolas militares no Estado de Mato Grosso, considerando os questionamentos expostos, que denunciam o ataque ao princípio constitucional de igualdade de acesso de todos a uma educação pública de qualidade e a afirmação de Alves; Toschi; Ferreira (2018, p.284) de que a expansão das escolas militares retoma "a lógica da exclusão e da educação dual, tão característica de nossa história"? Tomando esses questionamentos buscamos respostas através dos projetos aprovados ou dirigidos à Assembleia Legislativa do Estado de Mato Grosso (ALMT) pelos agentes públicos.

\section{JUSTIFICATIVA E CRITÉRIOS PARA EXPANSÃO DAS ESCOLAS MILITARES NO ESTADO DE MATO GROSSO}

A análise da documentação reunida, com base na Analise de Conteúdo de Laurence Bardin, possibilitou expor o conjunto de argumentos das autoridades públicas, visando à expansão do modelo de escola militar no Estado de Mato Grosso. A utilização da Análise de Conteúdo no corpus selecionado e analisado buscou elementos de unidades de registro (UR) e de unidades de conteúdo (UC) que sustentam as categorias, justificativas e critério. Também foi possível quantificar 
e estabelecer a frequência com que as unidades de registro (UR) ocorreram nos discursos e mensagem midiáticas, de modo a saber qual a importância de cada uma das URs na argumentação dos agentes públicos.

Constatamos que a justificativa das autoridades para a criação (expansão) das escolas militares se destaca, em ordem de frequência, nas seguintes URs: demanda da comunidade; organização e de qualidade de ensino; formação do cidadão; fator de segurança (Quadro 2).

\section{Quadro 2 - Unidades de registro da categoria justificativa, extraídas do material analisado, do período de 2015-2019, segundo a frequência com que foram mencionadas}

\begin{tabular}{|c|c|}
\hline CATEGORIA & UNIDADE DE REGISTRO/FREQUÊNCIA \\
\hline \multirow{3}{*}{ Justificativa } & Organização e de qualidade do ensino. (3) \\
\cline { 2 - 2 } & Preparar bons cidadãos/cidadania (2) \\
\cline { 2 - 2 } & Demanda da Comunidade (13) \\
\cline { 2 - 2 } & Fator Segurança (1) \\
\hline
\end{tabular}

Fonte: Sites oficiais do Governo do Estado e da Assembleia Legislativa de Mato Grosso. Elaborado pela Autora

A justificativa centrada na UR - "demanda da comunidade" e outras expressões correlacionadas - foi constatada em treze documentos de diferentes agentes públicos. Essa justificativa se apoia na população, fala em nome do povo, sem apresentar dados que expressem estudo da demanda ou de consulta popular sobre o desejo de haver uma escola militar em seu município no modelo já existente: uso das instalações das escolas públicas existentes; pagamento de mensalidades; prioridade dos filhos de militares e seus dependentes legais e seleção para entrada do público em geral, ou de outro modelo que não está muito claro.

\section{UNIDADES DE CONTEXTO}

"A população deseja esse modelo de educação, que tem como um dos objetivos, transformar a perspectiva de vida das nossas crianças"(Subsecretária do MEC, 2019).

"Há um contentamento muito grande por parte dos pais, alunos, mestres e da própria sociedade". (Deputado 1, 2016).

"Vinha sendo discutida bá algum tempo e que agora se concretiza. A escola deve dar aos jovens da região a expectativa de novas oportunidades” (Secretário de Educação, 2018). 
Há documentos em que a demanda da comunidade está associada à urgência e à necessidade de implantação, mas que carece de argumentos que sustentem a motivação da criação da escola militar em determinadas regiões, sua urgência e necessidade. Em alguns municípios, a solicitação de implantação foi dirigida aos superiores ${ }^{3}$, sem consulta à população, como demanda dela, e justificando a criação em nome da comunidade.

Na sequência, a UR - Organização e qualidade do ensino - é uma justificativa que está relacionada à moral e aos bons costumes como motivo para a criação e expansão das escolas militares, aliada à disciplina e, consequentemente, à hierarquia, determinando o bom desempenho dos alunos nas avaliações institucionais, somando-se aos valores cívicos, fazendo com que as escolas militares sejam apresentadas como instituições de ensino de qualidade.

\title{
UNIDADES DE CONTEXTO
}

\begin{abstract}
"As notas dos alunos no Enem (Exame Nacional do Ensino Médio) são das melhores do Estado. E a ideia é levar esse mesmo sistema e a mesma qualidade para o interior." (Governador, 2017).

"Formação de cidadãos dentro dos parâmetros do moral, dos bons costumes e valores cívicopatrióticos." (Deputado 3, 2017).

"Nós precisamos preparar boas pessoas, bons cidadãos, para que tenhamos não apenas um Mato Grosso melhor, mas uma nação melhor.” (Secretário de Segurança Pública, 2017).

"Desenvolver nos alunos o sentimento de amor à pátria e uma sadia mentalidade de disciplina consciente favorece o desempenho." (Deputado 5, 2017).
\end{abstract}

Essas escolas ganharam destaque nos últimos anos por alcançarem indicadores educacionais positivos pela imposição da ordem e da disciplina (SALDAÑA; CARAZZAI; GAMBA; TAKAHASHI, 2009). Mas esses mesmos autores afirmam que outras instituições de ensino, especialmente as públicas, sem a imposição da ordem e da disciplina, também alcançaram indicadores iguais ou superiores às instituições militares.

Os resultados delas são compatíveis com os de outros sistemas públicos de perfil semelhante, como algum tipo de seleção de estudantes, mas sem a rigidez militar. [...] Escolas militares têm desempenho similar ao de unidades com perfil parecido. Acima da média, centenas de colégios estaduais com alunos do mesmo perfil socioeconômico têm resultado melhor. (SALDAÑ ; CARAZZAI; GAMBA; TAKAHASHI, 2009, p.1).

3 Deputado Federal da cidade de Cáceres/MT enviou ao Comandante do Exército a solicitação de instalação de Escola "Cívico-militar" em Cáceres. 
No âmago da justificativa para a expansão das escolas militares, a qualidade do ensino nunca foi prioridade nas políticas educacionais do Estado de Mato Grosso, devendo-se pensar que se está implantando uma política de exclusão.

Por outro lado, a UR - Preparar bons cidadãos/cidadania - evidencia mais o conservadorismo da população brasileira, somado a personalidades autoritárias, do que propriamente uma formação humanista e democrática.

E, por fim, a UR - fator segurança - é uma justificativa que expressa a prevenção, a violência e a criminalidade. $O$ sentido dado é de que o combate à criminalidade deva ter início na escola, como se a escola fosse o espaço de formação da criminalidade; no entanto, a escola é o espaço que crianças e adolescentes em situação de vulnerabilidade têm para se protegerem do convívio com a violência e a criminalidade.

\section{UNIDADE DE CONTEXTO}

"Nós acreditamos na prevenção como a melhor medida no combate à criminalidade."(Secretário de Segurança Pública, 2018).

Quanto aos critérios adotados para a escolha das regiões para a implantação de escolas militares, constatamos que estes estão sendo exigidos dos agentes públicos para definir regiões e quantidades a fim de viabilizar de implantação, ver quadro 3 .

\section{Quadro 3 - Unidades de registro da categoria critérios, extraídas do material analisado, do período de 2015-2019, segundo a frequência com que foram mencionadas}

\begin{tabular}{|c|l|}
\hline CATEGORIA & \multicolumn{1}{c|}{ UNIDADE DE REGISTRO/ FREQUÊNCIA } \\
\hline Critérios & $\begin{array}{l}\text { Realização de estudos (1) } \\
\text { Informações sobre estudo da cidade, da necessidade de se implantar escolas militares } \\
\text { em determinada região. (1) }\end{array}$ \\
\hline
\end{tabular}

Fonte: Sites oficiais do Governo do Estado e da Assembleia Legislativa de Mato Grosso. Elaborado pela Autora.

Constatamos que há ausência de parâmetros técnicos da Secretaria de Estado de Educação para definir onde e quantas escolas desse modelo o Estado comporta e quando poderá criá-las sem onerar o erário público, sem impactar os recursos da SEDUC para a manutenção da rede de ensino público estadual existente. Assim, há solicitação de parlamentares para que a SEDUC se manifeste. 


\title{
UNIDADES DE CONTEXTO
}

\author{
"Estudo para viabilidade de implantaşão." (Deputado 5, 2018) \\ "Ausência de informações dos critérios adotados pela secretaria de educação, \\ quando da abertura de novas escolas militares. "(Deputado 6, 2018).
}

Os argumentos para justificar a criação das escolas e colégios militares no Estado de Mato Grosso não seguem uma narrativa sustentada em critérios científicos e dados comprovados empiricamente, mesmo porque eles não existem, e, pelo exposto, constata-se o senso comum nos argumentos.

1) são escolas de qualidade, apesar de não explicitar que qualidade é essa, nem quais meios são utilizados para alcançá-la; 2) reforça que estas escolas ensinam valores de disciplina e ordem; 3) as escolas são apresentadas como medida de segurança preventiva contra a violência que impera na sociedade. (ALVES; TOSCHI; FERREIRA, 2018, p. 276).

As alegações dos agentes públicos em seus discursos são mensagens que motivam a criação das escolas militares em Mato Grosso e coincidem com as reportagens que pautam a mídia e a propaganda governamental do Estado de Goiás sob o mesmo assunto. Envolvendo o conjunto dos argumentos que a população tem exigido do poder público e de vários governos, o momento histórico viabiliza uma rede de mensagens que, do mesmo modo que em outros Estados da Federação justifica a expansão das escolas públicas, tal como acontece em Mato Grosso. E em meio à expectativa de se reelegerem, os governadores apresentam à comunidade, como bandeira de campanha, a escola militar, como expectativa de um novo modelo de escola pública que tem qualidade de ensino, e a formação cidadã como valores sustentados na disciplina, na ordem, moral, nos bons costumes e em valores cívico-patrióticos, e a segurança como o controle sobre os discentes. Forma esta "de impor e manter a ordem, a moral e os bons costumes parece ganhar eco a partir das incertezas sociais e políticas em que vivemos." (FBSP, 2017, p. 23).

Segundo Alves; Toschi; Ferreira (2018), as escolas militares são objeto de desejo dos municípios, sendo colocadas no centro das negociações pelo poder local com a comunidade. 


\section{CONSIDERAÇÕES FINAIS}

Estamos diante de um fenômeno que ainda precisa ser mais bem estudado. A política de expansão das escolas e colégios militares, com foco na justificativa e critérios adotados, considerando-se que ela se apresenta regionalizada, no Mato Grosso o mecanismo ocorreu diferente da expansão em Goiás, Minas Gerais e da que está acontecendo no Distrito Federal.

No Mato Grosso, houve três momentos diferentes, que, reunidos, deram sustentação legal à política de expansão. Inicialmente, no ano de 2010, a inclusão da Escola Estadual da Polícia Militar "Tiradentes" na Estrutura Organizacional Básica da PMMT e no Sistema de Ensino da Polícia e do Corpo de Bombeiros Militares do Estado de Mato Grosso. Depois, em 2014, a reestruturação do Estatuto dos Militares do Estado de Mato Grosso, que integrou definitivamente a Escola "Tiradentes" à estrutura organizacional da PMMT, possibilitando, desse modo, que esse modelo de escola e colégio militar se replicasse no interior do Estado. E, por último, durante o governo de Pedro Taques, foi aprovada a Resolução Normativa $n^{\circ}$ 005/2015 do Conselho Estadual de Educação (MATO GROSSO, 2015), a qual fixou as normas de estrutura, organização e funcionamento das Escolas e Colégios Militares para oferta de Educação Básica do Sistema Estadual de Ensino de Mato Grosso. Todos esses passos deram, em 2017, ao Governo de Mato Grosso, as condições legais para a implantação e expansão de escolas militares no Estado, nos moldes da Escola Estadual da Polícia Militar “Tiradentes”, e possibilitaram a criação do Colégio Dom Pedro II do Corpo de Bombeiros Militar do Estado de Mato Grosso.

As escolas militares materializam e alimentam, com diferentes argumentos, o pensamento conservador e a personalidade autoritária que repousam na sociedade; por isso, muitos candidatos em/para diferentes cargos de poder incluíram e incluem em seus discursos a defesa da implantação de escolas militares em seu Estado, com o intuito de angariar votos para se elegerem/ reelegerem ou garantir a base de apoio do segmento conservador e autoritário da sociedade, como nos casos de Goiás e de Mato Grosso.

A criação e expansão das escolas/colégios militares se apresentam para a população como resultante da demanda popular e do segmento conservador e autoritário, que tenta impor sua régua regulatória à sociedade; também se apresenta como solução para a má qualidade do ensino, para a violência e a criminalidade.

$\mathrm{Na}$ argumentação para a expansão das escolas militares, a qualidade do ensino e, consequentemente, o melhor desempenho têm a lógica expressa na "ordem" e na "disciplina", na tese de que, com o controle sobre os discentes, através desses dois mecanismos, a aprendizagem melhorará. Para a qualidade 
do ensino não bastam ordem e disciplina, mas investimento na educação, que dê condições aos profissionais da rede pública de ensino de terem formação continuada, equipamentos e infraestrutura adequada às escolas, condições de aprendizagem com segurança; enfim, recursos que garantam, realmente, uma educação de qualidade e, quem sabe, em tempo integral.

A comunidade escolar não pode ser responsabilizada pelo sucateamento das escolas da rede de ensino público nem a crescente desmotivação dos professores como algo de foro íntimo. Ambos estão circunscritos à vontade política do governante, às suas políticas de governo, e não se pode nem é justo para com a escola pública que ela seja comparada em todos os níveis (material, didático-pedagógico, profissional e financeiro) com escolas e colégios militares que têm e são o que deveriam ter e ser todas as escolas públicas deste País.

A escola e o colégio militar podem, legalmente, cobrar taxas mensais, o que as faz ter recursos para pôr em prática projetos, programas e atividades extracurriculares. Já na escola pública, ao pretender realizar uma dessas atividades, o corpo docente tem que promover festas, bingos, gincanas, sorteios entre outros mecanismos. Nesse aspecto, uma questão desponta: de que maneira o governo do Estado de Mato Grosso pretende resolver a questão financeira da educação, considerando a quantidade de escolas e colégios militares com os quais se comprometeu, ao manter em vigência uma resolução segundo a qual os recursos para esse modelo de escola advirão da pasta da SEDUC, que necessita de volume financeiro para atender as necessidades materiais, pedagógicas e profissionais que o modelo exige e também ter o mesmo desembolso para as escolas da rede pública já existentes?

A cobrança de taxas mensais, que é possível, no modelo já consolidado de escola e colégio militar, estabelece subsistemas de ensino na rede pública. Um que servirá a uma elite que quer uma escola pública segura, com disciplina e qualidade de ensino, e o outro que se destinará ao segmento mais pobre da população, incluindo as crianças e os adolescentes que forem excluídos das escolas e colégios militares por não se adaptarem às normas de conduta e disciplina.

As escolas e colégios militares representam ameaça às escolas do sistema público de ensino. Ameaça à questão financeira, à medida que os parcos recursos terão que ser divididos com esse modelo de escola; ameaça à gestão democrática cuja luta proporcionou um avanço na educação; ameaça à qualidade do ensino que estará reservada a um modelo de escola destinada a uma elite, contrapondo-se ao direito de todos à educação de qualidade; desse modo, burla um dos princípios da democracia que é o princípio da igualdade ao ameaçar as políticas de inclusão, pois alguns, que se adaptarem ao modelo a ele terão acesso e os demais dele serão excluídos, o que parece ser uma forma de controle e segregação. 
A constatação de que nos argumentos dos agentes públicos do Estado de Mato Grosso não há critérios objetivos para a implantação e expansão das escolas e colégios militares compromete todo o sistema público de ensino do Estado. Além do mais, os agentes públicos não têm clareza, em suas justificativas, sobre a implantação e expansão, e se apoiam em argumentos frágeis, como a demanda das comunidades sem comprovação de que as mesmas os desejem. Manifestam-se em nome do povo sem que o povo, em sua ampla maioria, sendo o maior interessado, tenha informação e dados objetivos para fazer tal escolha.

E, por fim, diante do volume de escolas militares criadas no Estado e da resolução normativa do CEE/MT que fixa a estrutura, organização e funcionamento das mesmas, que atribui à SESP/MT a responsabilidade pela disponibilização de recursos humanos, isto é, policial militar para atuarem na direção, coordenação pedagógica e demais funções, questiona-se: os policiais militares de alta patente viram, na onda da militarização das escolas, um espaço para se alocarem confortavelmente, entrincheirando-se nas escolas, tirando do professor o seu espaço de atuação e formação? E deixou de ser função da polícia militar atender a segurança dos cidadãos?

\section{REFERÊNCIAS}

ALVES, Miriam Fábia;TOSCHI, Mirza Seabra; FERREIRA, Neusa Sousa Rêgo. A expansão dos colégios militares em Goiás in Revista Retratos da Escola. Brasília, v.12, n. 23, p.271-287, jul./dez.,2018. Disponível em <http://www. esforce.org.br> Acesso em 08 abr.,2019.

ANDRADE, Thiago. Deputados apresentam proposta de criação de novas escolas militares. Seduc. 06 abril de 2016. Disponível em < http://www2.seduc. $\mathrm{mt}$.gov.br/web/mt/-/3815380-deputados-apresentam-proposta-de-criacao-denovas-escolas-militares?inheritRedirect $=$ true $>$ Acesso em 08 abr.,2019.

BARDIN, Laurence. Análise de Conteúdo. Edições 70. Lisboa, Portugal.2010.

BRANDÃO, Rosane. Expansão da escola militar em MT é discutida durante simpósio. Seduc. 02 abril 2019. Disponível em < http://www.mt.gov.br/web/ seduc/-/11544256-expansao-da-escola-militar-em-mt-e-discutida-durantesimposio> Acesso em 06 abr.,2019. 
CAFARDO, Renata; JANSEN, Roberta.Estudantes de colégios militares custam três vezes mais ao País. Jornal O Estado de São Paulo. 25 agosto de 2018. Disponível em < https://politica.estadao.com.br/noticias/eleicoes,estudantesde-colegio-Omilitar-custam-tres-vezes-mais-ao-pais,70002473230> Acesso em 06 de abr.,2019.

CAMPOREZ, Patrik.Número de escolas públicas "militarizadas" no país cresce sob o pretexto de enquadrar os alunos. Revista Época. 23 de julho de 2018. Disponível em https://epoca.globo.com/numero-de-escolas-publicasmilitarizadas-no-pais-cresce-sob-pretexto-de-enquadrar-os-alunos-22904768. Acesso em 17.set., 2018.

DEVAUX, Sílvia.Convênio vai incentivar ações de prevenção à violência nas escolas estaduais. Secom, 9 de out., 2007. Não paginado. Mídia. Notícias. Educação Disponível em: < http://www.secom.mt.gov.br/imprime. php?cid=35763\&sid=25> Acesso em:. 11 abr.,2019.

FREITAS, Luiz Carlos de. Militarização da educação cria uma linha direta entre escolas para pobres e prisões. Jornal GGN. 10 de março de 2019. Mídia. Disponível em < https://jornalggn.com.br/artigos/militarizacao-da-educacaocria-uma-linha-direta-entre-escolas-para-pobres-e-prisoes/> Acesso em 09 abr.,2019.

FBSP. Medo da violência e o apoio ao autoritarismo no Brasil: índice de propensão ao apoio a posições autoritárias. Fórum Brasileiro de Segurança Pública. 2017. Disponível em: http://www.forumseguranca.org.br/wp-content/ uploads/2019/04/FBSP_indice_propensao_apoio_posicoes_autoritarios_2017_ relatorio.pdf Acesso em 14 jun.,2019.

MATO GROSSO. Lei Complementar no 8.171, de 22 de julho de 2004. Dispõe sobre a criação da Escola Estadual Dom Pedro II do Corpo de Bombeiros Militar do Estado de Mato Grosso e dá outras providências. Sad, 2004. Disponível em <http://www.sad-legislacao.mt.gov.br/Aplicativos/Sad-Legislacao/ legislacaosad.nsf/709f9c981a9d9f468425671300482be0/107aa57f4a44ce860425 6ee600663c61?OpenDocument> Acesso em 07.abr.,2019 
MATO GROSSO. Governo anuncia construção de mais um Colégio Militar Tiradentes em Cuiabá. 31 de julho de 2009. Secom. 2009 Disponível em < http://www5.sefaz.mt.gov.br/-/governo-anuncia-construcao-de-mais-umcolegio-militar-tiradentes-em-cuiaba >.Acesso em: 17.set.,2018.

MATO GROSSO. Lei Complementar no 386 de 5 de março de 2010. Dispõe sobre a estrutura organizacional básica da Polícia Militar do Estado de Mato Grosso e dá outras providências. Imprensa Oficial. 2010a.Disponível em < http://www. iomat.mt.gov.br/imprimir.htm?id=281624\&edi_id=2537 Acesso em 07 abr., 2019

MATO GROSSO. Lei Complementar n. 408 de 1 de julho de 2010b.Sistema de Ensino da Polícia e do Corpo de Bombeiro Militar do Estado de Mato. Legislativo. 2010b. Disponível em < http://www.pm.mt.gov.br/-/7748425-leicomplementar-n-408-de-01-de-julho-de-2010> Acesso em: 07 abr.,2019

MATO GROSSO. Lei Complementar no 555 de 29 de dezembro 2014. Dispõe sobre o Estatuto dos Militares do Estado de Mato Grosso. Legislativo. 2014. Disponível em < http://app1.sefaz.mt.gov.br/0425762E005567C5/250A3B13 0089C1CC042572ED0051D0A1/D314360ABFF2A92484257DC100692FB3> Acesso em 27 set.,2019.

MATO GROSSO. Resolução Normativa no 005/2015 de 29 de setembro de 2015. Fixa normas de estrutura, organização e funcionamento dos Colégios Militares para oferta de Educação Básica do Sistema Estadual de Ensino de Mato Grosso. Conselho Estadual de Educação, 2015. Disponível em < http://www.pm.mt. gov.br/documents /2459523/11865783/Portaria+005+CEE.pdf/5c6057c21260-b678-2623-644053eb1d9d> Acesso em 09 jun.,2019.

MATO GROSSO. Decreto n. 1.4275 de abril de 2018. Dispõe sobre a criação da Unidade Escolar que adiante menciona. Imprensa Oficial. 2018 Disponível em: $\quad$ https://www.iomat.mt.gov.br/buscanova/\#/p=1\&q=Decreto $\% 20$ n $\%$ C2\%BA $\% 201.427 \% 20 \mathrm{de} \% 20 \% 2005 \% 20 \mathrm{de} \% 20$ abril $\% 202018$. Acesso em 15.out.2019

PACHECO, Valeria. Colégios públicos com gestão militar chegam a Brasília na era Bolsonaro. AFP. 28 de janeiro de 2019. Disponível em < https://www. folhape.com.br/folhape/nwsPrint.aspx?mId=97698 > Acesso em 09 abr.,2019. 
POLÍCIA MILITAR. Ensino- E. Tiradentes Cuiabá - Histórico. 2000

Disponível em < http://www.pm.mt.gov.br/colegio-tiradentes-historico> Acesso em 07 abr.,2019.

SALDAÑA, Paulo; CARAZZAI, Estelita Hass; GAMBA, Estevão; TAKAHASHI, Fábio. Escolas militares e colégios civis com mesmo perfil têm desempenho similar. Folha de São Paulo. 18 de fevereiro de 2019. Educação. Disponível em:< https://www1.folha.uol.com.br/educacao/2019/02/escolas-militares-ecolegios-civis-com-mesmo-perfil-tem-desempenho-similar.shtml> Acesso em: 17 abr.,2019

SANTANA, Wallmar. Decreto cria mais três escolas militares em Mato Grosso. 2017. Imprensa Oficial. 28 de março de 2017. Educação. Disponível em: http:/ / www.mt.gov.br/-/6027062-decreto-cria-mais-tres-escolas-militares-em-matogrosso Acesso em: 20 out.,2019.

TEIXEIRA,Matheus; CARNEIRO,Luiz Orlando. STF permite cobrança de mensalidade em colégios militares. Blog Jota. 24 de outubro de 2018. Disponível em< https://www.jota.info/stf/do-supremo/stf-permite-cobranca-demensalidade-em-colegios-militares-24102018. Acesso em 06 abr.,2019.

MARIA DO HORTO SALLES TIELLET é Doutora em Educação pela Universidade do Vale dos Sinos. Professora sênior do Programa de Pós-Graduação em Educação da Universidade do Estado de Mato Grosso. Cáceres, Mato Grosso. Brasil

E-mail: mariadohorto_tiellet@yahoo.com.br e tiellet.maria@unemat.br ORCID: https://orcid.org/0000-0002-1794-7274

Recebido em junho de 2019 Aprovado em setembro de 2019 